\title{
ANÁLISE DA COBERTURA VEGETAL E DA TEMPERATURA DE SUPERFÍCIE NA REGIÃO URBANA E PERIURBANA DO MUNICÍPIO DE SANTARÉM/PA
}

\author{
Everson Raylan Silva dos Santos ${ }^{1}$ \\ Barbara Eleonora Santos Teixeira² \\ Everton Cristo de Almeida ${ }^{3}$ \\ Ítalla Cristina Neves ${ }^{4}$ \\ Ademir Terra ${ }^{5}$
}

Resumo: As atividades antrópicas vêm, há tempos, mudando as características da superfície terrestre e estudar a dinâmica dessas transformações é importante para executar medidas que possam tornar o ambiente um lugar favorável às condições de vida. Nesse sentido, este trabalho avaliou por meio dos métodos MAXVER e METRIC/SEBAL, as mudanças ocorridas na cobertura vegetal e na temperatura de superfície nos anos de 1986 e de 2010, no município de Santarém, no estado do Pará, e constatou o expressivo aumento das áreas de solo exposto e da elevação da temperatura de superfície relacionados diretamente com a supressão da vegetação e predominância de cobertura asfáltica e verticalização dos prédios.

Palavras-chave: Sistemas de Informações Geográficas (SIGs). Urbanização. Cobertura Vegetal. Conforto térmico. Santarém.

\section{ANALYSIS OF VEGETABLE COVERAGE AND SURFACE TEMPERATURE IN THE URBAN AND PERIURBAN REGION OF THE MUNICIPALITY OF SANTARÉM/PA}

Abstract: Anthropic activities have long been changing the characteristics of the terrestrial surface and studying the dynamics of these transformations is important to implement measures that can make the environment a place favorable to living conditions. In this sense, this work evaluated by means of the methods MAXVER and METRIC / SEBAL, the changes occurred in the vegetation cover and the surface temperature in the years of 1986 and 2010, in the municipality of Santarém, in the state of Pará, and verified the significant increase of the areas of exposed soil and of the elevation of the surface temperature directly related to the suppression of vegetation and predominance of asphalt cover and verticalization of the buildings.

Keywords: Geographic Information Systems (SIGs). Urbanization. Vegetal Cover. Thermal Comfort. Santarém.

\footnotetext{
1 Universidade Federal do Oeste do Pará - UFOPA, Instituto de Biodiversidade e Florestas, Santarém, Brasil, Everson_raylan@hotmail.com, https://orcid.org/0000-0002-2909-1220

2 Universidade Federal do Pará - UFPA, Instituto de Filosofia e Ciências Humanas - IFCH, Faculdade de Geografia e Geografia - FGC, Belém, Brasil, barbarageo2010@hotmail.com, https://orcid.org/0000-0002-3650-6682

${ }_{3}^{3}$ Universidade Federal do Oeste do Pará - UFOPA, Instituto de Biodiversidade e Florestas, Santarém, Brasil, evertonselva30@gmail.com, https://orcid.org/0000-0002-3039-5440

${ }^{4}$ Universidade Federal do Pará - UFPA, Instituto de Filosofia e Ciências Humanas - IFCH, Faculdade de Geografia e Geografia - FGC, Belém, Brasil, italla.neves1605@gmail.com, https://orcid.org/00000003-1675-7908

${ }^{5}$ Universidade Estadual do Maranhão - UEMA, Departamento de História e Geografia, São Luís, Brasil, ademir.terra@outlook.com.br,https://orcid.org/0000-0002-5304-3341
} 


\section{ANÁLISIS DE LA CUBIERTA VEGETAL Y DE LA TEMPERATURA DE SUPERFICIE EN LA REGIÓN URBANA Y PERIURBANA DEL MUNICIPIO DE SANTARÉM/PA}

Resumen: Las actividades antrópicas vienen, hace tiempo, cambiando las características de la superficie terrestre y estudiando la dinámica de esas transformaciones, es importante para ejecutar medidas que puedan hacer del ambiente un lugar favorable a las condiciones de vida. En este sentido, este trabajo evaluó por medio de los métodos MAXVER y METRIC / SEBAL, los cambios ocurridos en la cobertura vegetal y en la temperatura superficial en los años 1986 y 2010, en el municipio de Santarém, en el estado de Pará, y constató el expresivo aumento de las áreas de suelo expuesto y de la elevación de la temperatura de superficie relacionadas directamente con la supresión de la vegetación y predominancia de cobertura asfáltica y verticalización de los edificios.

Palabras clave: Sistemas de Información Geográfica (SIG). Urbanización. Cubierta Vegetal. Confort Térmico. Santarém.

\section{Introdução}

Ao longo do tempo, a Amazônia vem sofrendo com a intensa mudança na superfície terrestre em razão do grande aumento populacional. Essa mudança é resultado de um processo de expansão que teve início na década de 1970, incentivado pelas políticas de facilitação de acesso a terra pelo Plano de Integração Nacional. Mais tarde, com a necessidade de produzir alimentos para atender à demanda dessa crescente população, as áreas desmatadas foram dando lugar à agropecuária. Esse processo se intensificou com a abertura da rodovia federal BR 163, que liga a cidade de Cuiabá, no Mato Grosso, à Santarém, no Pará, juntamente com o início das atividades do terminal da multinacional Cargill, em Santarém empresa responsável pelo escoamento de grãos das comunidades locais e da região do Centro-Oeste do Brasil - no ano de 2003, aliadas à facilidade de compra de terra a preços baixos por produtores de vários lugares do país, contribuíram para a redução acelerada de áreas de florestas nativas, e forte migração para a cidade (TORRES, 2017).

Todas essas dinâmicas tiveram influência direta na cidade e sua qualidade ambiental, pois é conhecido que a cobertura vegetal colabora com a amenização da temperatura nos espaços públicos. Desta forma, nos questionamos quais as alterações sofridas na temperatura da área urbana e periurbana do município de Santarém-Pará, nos períodos em que se intensifica atividade de desmatamento dessa região? 
Diante disso, o objetivo deste trabalho é avaliar, com o auxílio de imagens de satélite e técnicas de geoprocessamento, as mudanças ocorridas na cobertura do solo e na temperatura de superfície nos anos de 1986 e 2010, lapso temporal de 24 anos, na área urbana e periurbana do município de Santarém, no estado do Pará.

Esta análise é de fundamental importância para os estudos ambientais e de políticas públicas da região, pois além de demostrar de forma clara, através de dados de geoprocessamento, as mudanças no ambiente e na temperatura da área urbana e periurbana do município, confirma as implicações causadas pela retirada da cobertura vegetal do solo para fins de produção agroeconômica na região amazônica.

Em razão das constantes mudanças no ambiente $\mathrm{e}$ do aumento populacional, é importante conhecer as dinâmicas ambientais e, com isso, adotar medidas para tornar o ambiente mais adequado termicamente e proporcionar melhor qualidade de vida.

\section{Área de estudo}

Santarém está situada no estado do Pará, no norte do Brasil, na mesorregião do Baixo Amazonas e microrregião de Santarém, banhada pelos rios Tapajós e Amazonas. Está sob as coordenadas geográficas $2^{\circ} 24^{\prime} 52^{\prime \prime} \mathrm{S}$ e $54^{\circ} 42^{\prime} 36^{\prime \prime} \mathrm{W}$ (Figura 2), ocupando uma área de 22.887,080 km². De acordo com dados do Instituto Brasileiro de Geografia e Estatística (IBGE), em 2017 a população estimada era de 296,302 (duzentos e noventa e seis mil e trezentos e dois) habitantes. A cidade se tornou um centro universitário e atrai uma grande quantidade de estudantes das cidades vizinhas. É também o principal centro urbano financeiro, comercial e cultural do oeste paraense (Prefeitura Municipal de Santarém, 2018). De acordo com Gonçalves et al (2012), o clima da cidade é quente e úmido, com temperaturas mais altas ocorrentes entre os meses de junho e novembro. 


\section{Figura 1: Localização da cidade de Santarém/PA}

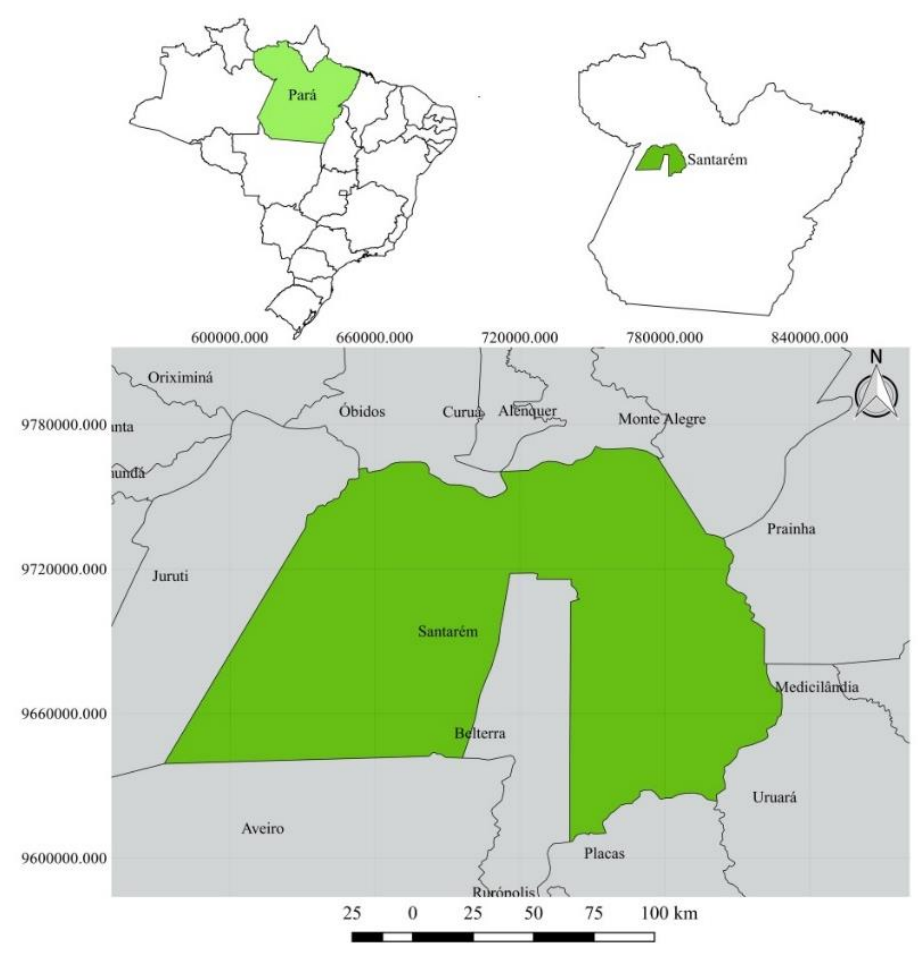

Em virtude da grande extensão territorial do município de Santarém e das grandes áreas cobertas por corpos d'água, além da dificuldade em encontrar imagens com grandes extensões sem a presença de nuvens, optou-se por delimitar um polígono envolvendo as áreas mais povoadas, excluindo as áreas que continham grandes porções de nuvens e incluindo as adjacências das rodovias BR 163, PA 370, PA 433, PA 453 e PA 457, que corresponde à área urbana e periurbana do município, conforme a Figura 2.

\section{Figura 2: Localização da área de estudo}

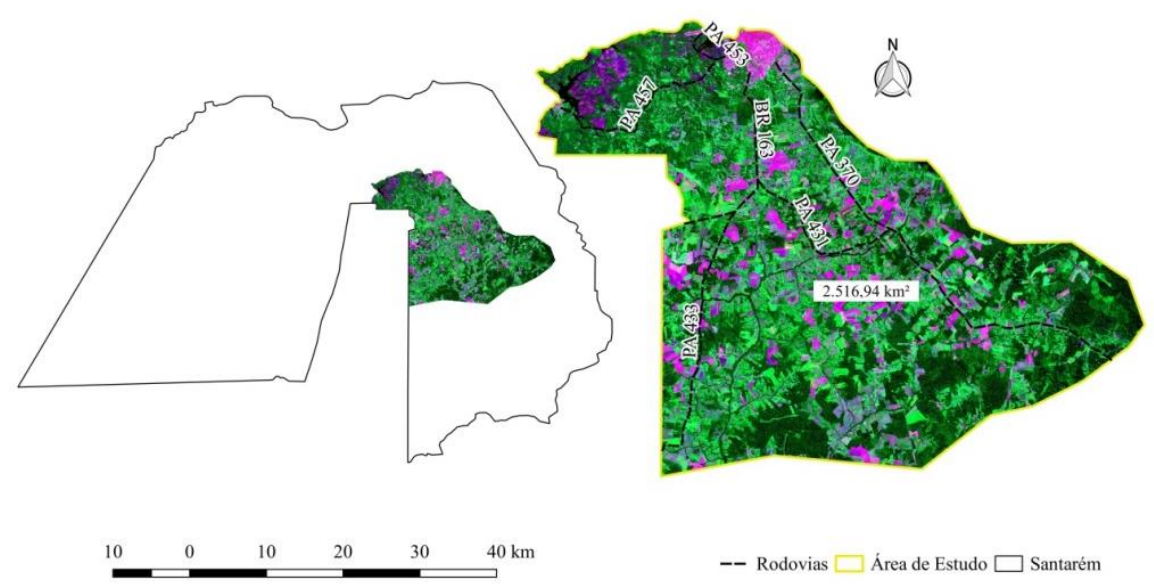




\section{Materiais utilizados}

Neste trabalho, foram utilizadas as bandas 3 (vermelho), 4 (IV próximo) e 10 (IV termal) das imagens dos anos de 1986 e 2010 do satélite Landsat 5, obtidas gratuitamente no catálogo de imagens do Instituto Nacional de Pesquisas Espaciais (Inpe) http://www.dgi.inpe.br/CDSR/. Todas as imagens são da órbita/ponto 227/62, que recobre o município de Santarém. Além disso, foram utilizados o SIG QGIS, versão 2.18, software de código aberto, amplamente empregado no processamento de imagens de satélites em pesquisas com geoprocessamento, que pode ser obtido no site https://qgis.org/pt_BR/site/; e o software Google Earth Pro, versão 7.1, utilizado no esclarecimento de dúvidas no momento de definir as amostras de classificação.

Com o intuito de evitar eventuais discrepâncias nos resultados, foram obtidas imagens de épocas próximas do ano. A imagem do ano de 1986 é datada de 17 de outubro e a do ano de 2010 é do dia 29 de junho. Além disso, estas imagens foram escolhidas por apresentarem pouca cobertura de nuvens, pois a presença destas superestimaria os resultados.

\section{Pré-processamento as imagens de satélites}

As imagens obtidas no site do Inpe eram projetadas para o sistema de coordenadas Datum WGS 84. Por isso, foi necessário fazer a reprojeção destas para o Datum SIRGAS 2000 (sistema oficialmente adotado no Brasil). Após isso, foi recortado somente o polígono da área de estudo para, assim, dar início aos demais procedimentos.

\section{Classificação da cobertura do solo}

A classificação da cobertura do solo pode ser feita de modo não supervisionada, quando o algoritmo, utilizando seus parâmetros próprios, classifica a imagem sem interferência humana; de forma supervisionada, com base em amostras definidas pelo pesquisador; e de modo híbrido, em que a parte é não supervisionada e parte é supervisionada. 
Entre os métodos mais conhecidos de classificação supervisionada que analisam as imagens pixel a pixel, estão os métodos do paralelepípedo, no qual são indicados os valores máximo e mínimo nos histogramas, e os pixels são incluídos nas classes conforme esses valores indicados; da máxima verossimilhança (MAXVER), que, com base nas amostras definidas, calcula, por meio de estatísticas, a probabilidade de cada pixel pertencer à determinada classe; e da mínima distância, que classifica o pixel de acordo com as médias dos valores dos histogramas e a mínima distância entre cada pixel, pois, se um pixel estiver próximo de outro com características parecidas, a probabilidade de estes pertencerem à mesma classe é maior (BARBOSA, 2009).

Por fornecer classificações com mais precisões e ser um dos mais eficientes e utilizados, conforme constatado por Barbosa (2009), Grondona (2009), Cohenca e Carvalho (2015), Nery et al (2013) e Dermarchi, Sartori e Zimback (2011), a técnica utilizada para classificar as imagens deste trabalho foi a classificação supervisionada por meio do método MAXVER.

Com o auxílio do Semi-Automatic Classification Plugin, complemento instalado no QGIS, classificaram-se as imagens nas 7 classes seguintes: floresta, vegetação rala, área urbanizada, solo exposto, corpo d'água, nuvem e sombra de nuvem. Optou-se por utilizar classes mais genéricas de cobertura do solo para evitar grandes confusões no processo de classificação em razão da média resolução das imagens fornecidas pelo satélite Landsat 5 , já que cada pixel tem $30 \times 30$ metros.

O software Google Earth Pro serviu de instrumento para esclarecer dúvidas no momento de definir as amostras de classificação, pois ele apresenta imagens de alta resolução e, por meio destas, pode ser feita a distinção entre objetos na superfície terrestre.

Após classificadas, as imagens foram submetidas à avaliação de qualidade da classificação. Por destacar-se entre os meios mais utilizados para avaliação da precisão de classificação de imagens, utilizou-se o índice Kappa o qual, por meio do resultado de análises estatísticas, baseadas em matrizes de erros - que comparam o resultado das classificações com os valores das amostras definidas e determina se estas estão corretas - indica a qualidade da classificação (NERY et al, 2013).

O índice Kappa é obtido por meio da equação 1 :

$$
\mathrm{k}=\frac{\mathrm{N} \sum \mathrm{x}_{i \bar{i}}-\sum \mathrm{x}_{i}+\mathrm{x}_{+i \bar{i}}}{\mathrm{~N}^{2}-\sum \mathrm{x}_{i}+\mathrm{x}_{+i}}
$$


Sendo: $\mathrm{N}=$ número total de amostras; $\Sigma \mathrm{Xii}=$ soma do número das amostras corretas nas linhas e colunas; $\mathrm{Xi}+=$ soma linear $\mathbf{X}+\mathrm{i}=$ soma colinear.

Os valores do índice Kappa variam de 0 a 1, leia-se: 0\% e 100\%, em que 0 não apresenta nenhuma concordância e 1 apresenta excelente concordância, conforme a Tabela 1.

\section{Tabela 1: Valores do índice Kappa}

\begin{tabular}{cc}
\hline $\begin{array}{c}\text { Índice } \\
\text { Kappa }\end{array}$ & Concordância \\
\hline$<0$ & $\begin{array}{c}\text { Sem } \\
\text { concordância }\end{array}$ \\
0.00 a 0.19 & Pobre \\
0.20 a 0.39 & Fraca \\
0.40 a 0.59 & Moderada \\
0.60 a 0.79 & Forte \\
0.80 a 1.00 & Excelente \\
\hline
\end{tabular}

Fonte: Landis e Koch (1977), apud Nery et al (2013).

A Figura 3 mostra o fluxograma simplificado do processo de classificação das imagens.

Figura 3: Fluxograma da classificação das imagens

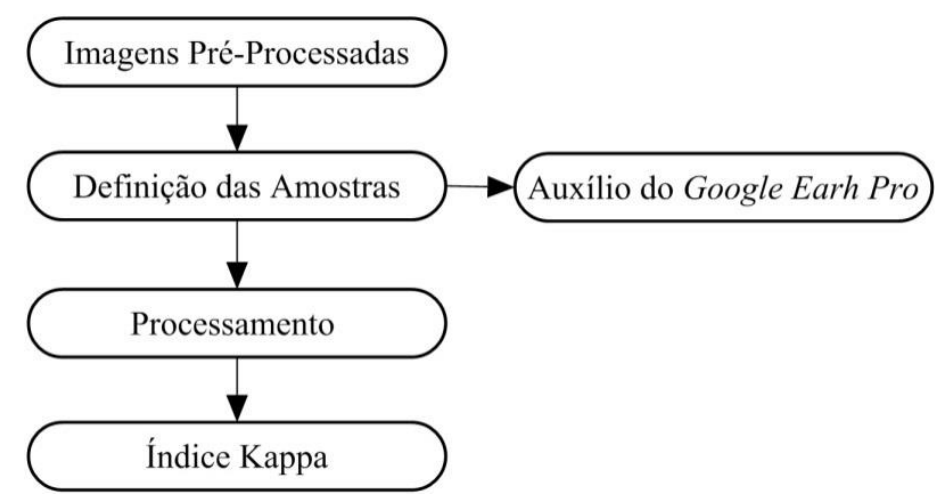

\section{Obtenção da temperatura}

Cada pixel das imagens de satélite é composto por números digitais $(D M)$ em tons de cinza, e esses números digitais podem ser convertidos em valores de temperatura. Mas, para obter a temperatura de superfície por meio de imagens de satélites, é necessária a aplicação de técnicas que corrijam os efeitos atmosféricos sofridos pelas imagens. 
Conforme exposto por Ideião et al. (2008), dentre os modelos de conversão de $D N$ para valores de temperatura, destacam-se o algoritmo Surface Energy Balance Algorithm for Land (SEBAL), desenvolvido por Bastiaanssen em 1998; e o Mapping Evapotranspiration at High Resolution and With Internalized Calibration (METRIC), que é uma adaptação do modelo SEBAL, desenvolvido e detalhado por Allen et al. (2005).

O modelo METRIC/SEBAL, utilizado neste trabalho, foi validado por diversos autores, como Ideião et al (2008); Cunha, Rufino, Ideião (2009); Machado et al (2011); Silva et al. (2012); e Pereira et al (2017).

Para a obtenção dos valores de temperatura, foram utilizadas as bandas 3 (vermelho), 4 (infravermelho próximo) e 6 (termal) das imagens de 1986 e 2010 do Landsat 5. Conforme detalhado por Allen et al (2005), para obter os valores de temperatura por meio do METRIC/SEBAL, é necessário executar as etapas abaixo descriminadas.

O primeiro passo para conversão de $D N$ em valores de temperatura é a conversão de $D N$ para radiância espectral monocromática das bandas do vermelho e infravermelho próximo. A radiância espectral é a intensidade de fluxo radiante emitido por pixel da imagem podendo ser obtida por meio da equação 2 :

$$
L_{\lambda i}=\left[\left(L_{\lambda \max }-L_{\lambda \min }\right) / 255\right] \cdot D N-L_{\lambda \min }
$$

Em que $L_{\lambda i}$ min e $L_{\lambda i}$ max são os valores da radiância máxima e mínima de cada banda, de acordo com a Tabela 3; o valor 255 é a intensidade com que variam as tonalidades dos valores de $D N$. Para o Landsat 5 , o valor varia de 0 a 255 porque suas imagens possuem 8 bits por pixel.

Tabela 2: Valores de LAi min, LAi max e irradiância solar espectral para cada banda do sensor TM

\begin{tabular}{cccc}
\hline Bandas & $\mathrm{L}_{\lambda_{i}(\min )}$ & $\mathrm{L}_{\lambda_{i}(\max )}$ & Irradiância solar \\
\hline 1 & $-1,52$ & 193,0 & 1957 \\
2 & $-2,84$ & 365,0 & 1826 \\
3 & $-1,17$ & 264,0 & 1554 \\
4 & $-1,51$ & 221,0 & 1036 \\
5 & $-0,37$ & 30,2 & 215,0 \\
6 & 1,2378 & 15,303 & - \\
7 & $-0,15$ & 16,5 & 80,67 \\
\hline
\end{tabular}

Fonte: Chander e Markhan (2003), apud Braga (2014) (adaptado). 
Após a obtenção da radiância, esta é convertida em reflectância espectral aparente, que é definida como a relação entre a energia emitida e refletida sobre uma superfície, sendo obtida pela equação 3 :

$$
r_{a, i}=\pi \cdot L_{\lambda i} / E_{i} \cdot \cos \theta \cdot d r
$$

Para compreensão da fórmula, $r_{a, i}$ é a reflectância espectral; $L_{\lambda i}$ é a radiância espectral obtida anteriormente; $E_{i}$ é o valor da irradiância solar espectral contido na Tabela 3; $\theta$ é o ângulo zenital solar obtido pela equação 4:

$$
\cos \theta=\cos \left(\frac{\pi}{2}-E\right)
$$

Em que $E$ é o ângulo de elevação do sol contido nos metadados das imagens.

A variável $d r$ da equação 3 é o inverso do quadrado da distância entre a terra e o sol, valor que é encontrado por meio da equação 5 :

$$
d_{r}=1+0,033 \cdot \cos (D A A .2 \cdot \pi / 365)
$$

Em que DDA é a data de passagem do sensor, contado pelo calendário juliano.

Os valores de reflectância das bandas do vermelho e do infravermelho próximo são convertidos em índices de vegetação, pois, por meio destes, é possível identificar a presença ou ausência de vegetação na superfície.

O Índice de Vegetação Ajustado ao Solo (Savi) é um índice de vegetação que, no seu cômputo, ameniza os efeitos sofridos pelo solo, como a presença de árvores com dosséis grandes que poderiam superestimar os resultados, por exemplo. Este índice é calculado pela equação 6 :

$$
S A V I=(1+L) \cdot\left(r_{i v p}-r_{v}\right) /\left(L+r_{i v p}+r_{v}\right)
$$

Em que L é uma constante de valor 0,5; rivp é a reflectância da banda do infravermelho próximo; e rvé a reflectância da banda do vermelho.

O outro índice de vegetação a ser calculado é o Índice de Área Foliar (IAF), que indica o índice de biomassa de cada pixel das imagens, encontrado por meio da equação 7 :

$$
I A F=-\ln ((0,69-S A V I / 0,59) / 0,91)
$$

Os valores 0,$69 ; 0,59 ;$ e 0,91 são constantes da fórmula.

O cálculo da emissividade de cada pixel $\left(E_{N B}\right)$ da banda termal é necessário, pois os pixels não são corpos negros - estes são objetos hipotéticos que absorvem 
toda a energia incidente sobre eles. Portanto, esse valor é necessário para a fórmula da obtenção de temperatura, sendo calculado pela equação 8 :

$$
\mathrm{E}_{\mathrm{NB}}=0,97+0,00331 . \mathrm{IAF}
$$

Os valores 0,97 e 0,0031 são constantes e, para valores de IAF menores que 3 , o ENB é considerado 0,98.

Depois de todas as etapas anteriores, finalmente é possível obter, em graus Kelvin (K), a temperatura de superfície por meio da equação de Plank invertida (equação 9):

$$
T_{s k}=K_{2} / \ln \left(E_{N B} \cdot K_{1} / L_{\lambda 6}+1\right)
$$

Em que $\mathrm{K}_{1}$ e $\mathrm{K}_{2}$ são constantes de valor 607,76 e 1260,56, respectivamente; e $L_{\lambda t}$ é a radiância espectral das bandas termais.

Os valores de temperatura obtidos em graus $\mathrm{K}$ foram convertidos para graus Celsius $\left({ }^{\circ} \mathrm{C}\right)$, por meio da equação 10 :

$$
T \stackrel{\circ}{ } \mathrm{C})=\mathrm{T}_{\mathrm{sk}}-273,15
$$

A Figura 5 mostra o fluxograma de obtenção de temperatura pelo método METRIC/SEBAL:

Figura 4: Fluxograma de obtenção de temperatura

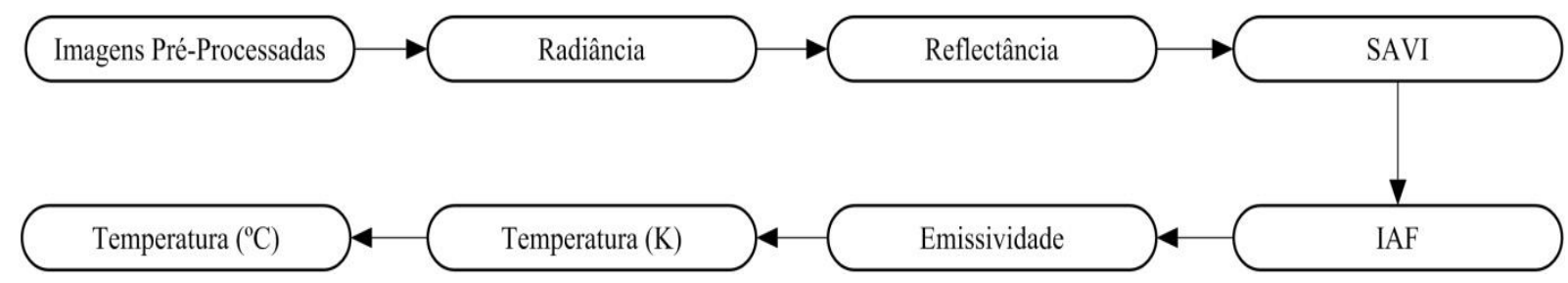

\section{Resultados e Discussão \\ Classificação da cobertura do solo}

Após a classificação da cobertura do solo no SIG QGIS, foram gerados mapas temáticos para melhor visualização. A Figura 6 mostra a cobertura do solo no ano de 1986. Nela é possível perceber a predominância de florestas e de vegetação rala e pouca área urbanizada e de solo exposto.

As áreas urbanizadas se concentravam mais na área ao norte do município, conforme destacado pela elipse amarela; as áreas de solo exposto eram menos 
presentes, tendo sido quantidade mais expressiva para essa classe detectada na área circulada pela elipse vermelha. Essa área fica próxima ao distrito de Alter do Chão e apresenta a vegetação do tipo savana, que é caracterizada por apresentar a predominância de gramíneas e árvores esparsas. Em razão da média resolução das imagens de satélite e da resposta espectral muito parecida com a do solo exposto, essas áreas podem ser facilmente confundidas no processo de classificação. Mesmo nas adjacências das rodovias, é possível perceber que as áreas de florestas e vegetação rala eram bastante extensas e densas, como destacado pela elipse azul.

Figura 5: Classificação da cobertura do solo no ano de 1986

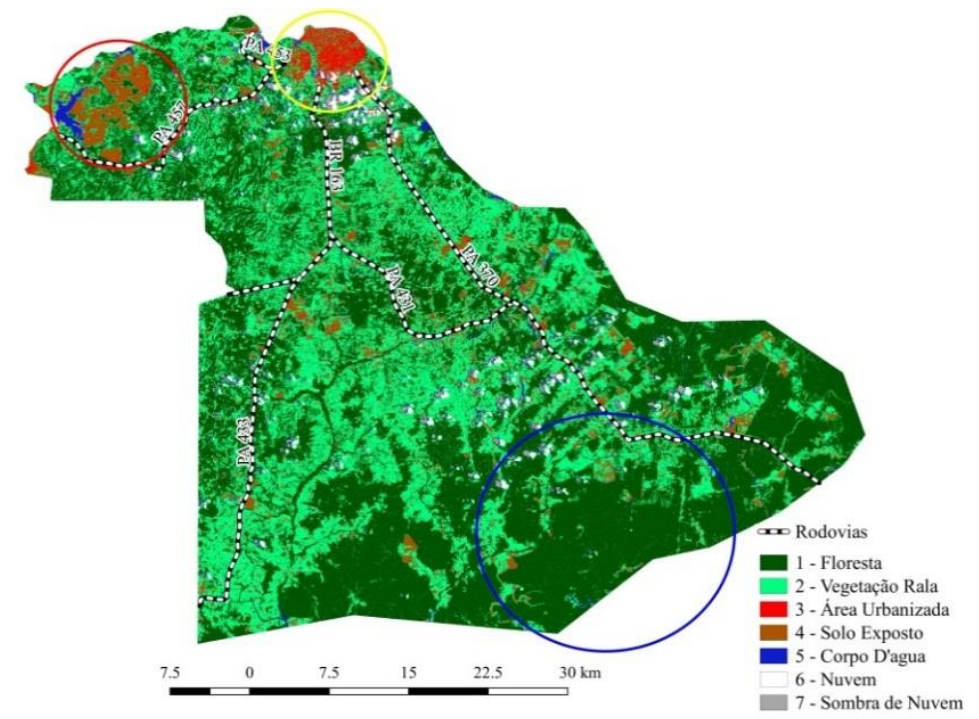

A acurácia dessa classificação, calculada pelo índice Kappa, é apresentada na Tabela 3.

Tabela 3: Índice Kappa para a classificação da cobertura do solo do ano de 1986

\begin{tabular}{ccc}
\hline Classe & $\begin{array}{c}\text { Índice Kappa } \\
(\%)\end{array}$ & Concordância \\
\hline Floresta & 96 & Excelente \\
Vegetação rala & 92 & Excelente \\
Área urbanizada & 82 & Excelente \\
Solo exposto & 91 & Excelente \\
Corpo d'água & 93 & Excelente \\
Nuvem & 99 & Excelente \\
Sombra de nuvem & 84 & Excelente \\
\hline
\end{tabular}


Conforme mostra os índices Kappa, todas as classes obtiveram um valor acima de $80 \%$, o que confirma a alta probabilidade de as classes pertencerem às amostras determinadas na fase de treinamento do algoritmo.

Até o ano de 2010, a cobertura do solo já havia sofrido grandes mudanças. É facilmente perceptível as áreas urbanizadas e as áreas de solo exposto se espalharam pelo município, principalmente próximo às rodovias. Consequentemente, as áreas com florestas e vegetação rala tenderam a diminuir, como mostra a Figura 6.

Figura 6: Classificação da cobertura do solo no ano de 2010

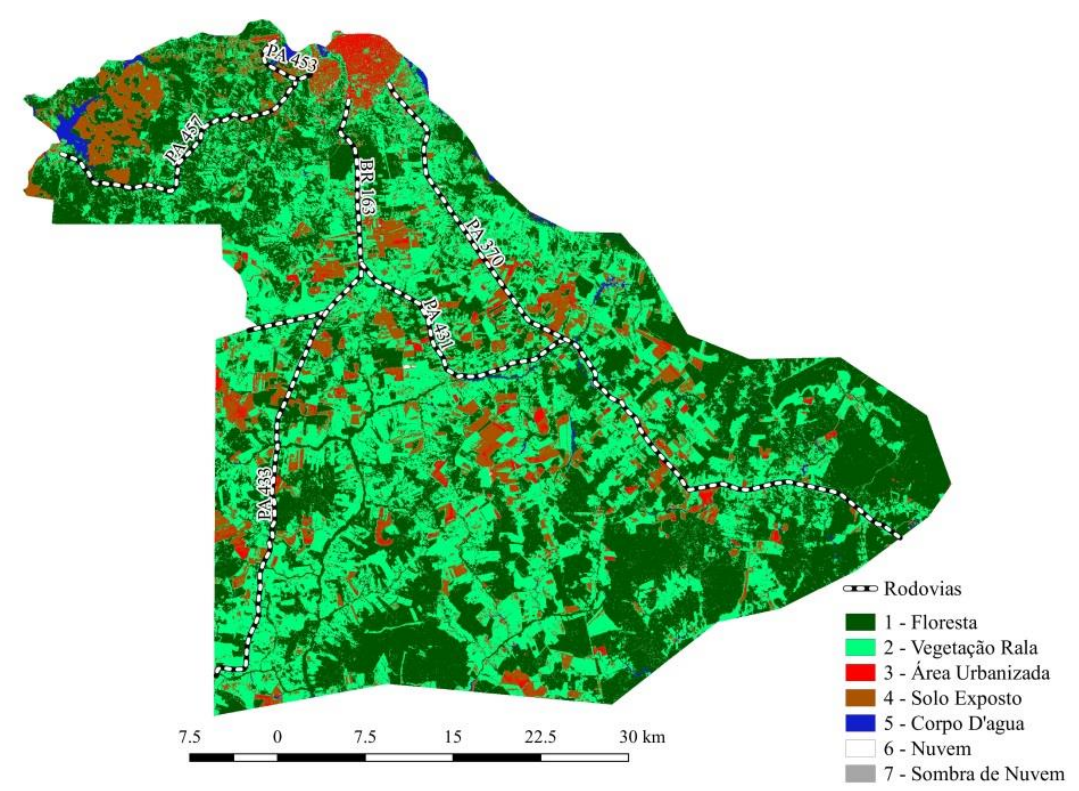

Os valores do índice Kappa para a classificação da imagem do ano de 2010, assim como para a classificação da imagem do ano de 1986 foi bastante satisfatória (Tabela 4).

Tabela 4: Índice Kappa para a classificação da cobertura do solo do ano de 2010

\begin{tabular}{ccc}
\hline Classe & $\begin{array}{c}\text { Índice Kappa } \\
(\%)\end{array}$ & Concordância \\
\hline Floresta & 98 & Excelente \\
Vegetação rala & 92 & Excelente \\
Área urbanizada & 56 & Moderada \\
Solo exposto & 89 & Excelente \\
Corpo d'água & 99 & Excelente \\
Nuvem & 68 & Forte \\
Sombra de nuvem & 0 & Pobre \\
\hline
\end{tabular}


A classe sombra de nuvem apresentou o índice Kappa 0\% em razão da ausência dessa classe na imagem. Pode ter ocorrido de, na hora de passagem do sensor, a sombra estar exatamente embaixo da nuvem, tornando, portanto, impossível a sua captação.

O índice Kappa de $56 \%$ para a classe de área urbanizada mostra que $44 \%$ das áreas definidas como pertencentes a essa classe podem pertencer a outras. Conforme afirmado por Alves, Florenzano e Pereira (2010), essa confusão pode ter ocorrido principalmente com as áreas de solo exposto, mas isso acaba sendo inevitável porque suas respostas espectrais são muito parecidas, além de serem visualmente semelhantes por meio de uma imagem de satélite de média resolução.

A Tabela 5 mostra as diferenças quantitativas das mudanças ocorridas na cobertura do solo.

Tabela 5: Valores quantitativos das classes de cobertura do solo

\begin{tabular}{|c|c|c|c|c|}
\hline Classe & $\begin{array}{c}\text { Área em } 1986 \\
\left(\mathrm{~km}^{2}\right)\end{array}$ & $\begin{array}{c}\text { Área em } 2010 \\
\left(\mathrm{~km}^{2}\right)\end{array}$ & $\begin{array}{c}\text { Mudança } \\
\left(\mathrm{km}^{2}\right)\end{array}$ & $\%$ \\
\hline Floresta & $1.296,01$ & $1.121,00$ & $-175,01$ & $-13,5$ \\
\hline Vegetação rala & 902,25 & $1.040,00$ & $+137,75$ & $\stackrel{+}{13,25}$ \\
\hline Área urbanizada & 25,55 & 64,07 & $+38,52$ & $\stackrel{+}{60,11}$ \\
\hline Solo exposto & 189,91 & 268,04 & $+78,13$ & $\stackrel{+}{+} 14$ \\
\hline Corpo d'água & 42,72 & 17,40 & $-25,32$ & 59,27 \\
\hline Nuvem & 35,12 & 1,07 & - & - \\
\hline Sombra de nuvem & 18,97 & 0,00 & - & - \\
\hline
\end{tabular}

Total da área de estudo

$2.516,94 \mathrm{~km}^{2}$

(-) diminuição; (+) aumento.

De 1986 a 2010, houve uma diminuição de $175,01 \mathrm{~km}^{2}$ de áreas ocupadas por florestas, equivalente a $13,5 \%$. Como mostrado na Figura 7 , essa diminuição ocorreu principalmente próximo às rodovias que cortam o município. Grande parte dessas áreas são utilizadas para plantação de grãos como arroz, soja e milho. 
A área urbanizada teve um aumento de $60,11 \%$ nesse período de 24 anos. Como resultado desse aumento e da diminuição das áreas de florestas, as áreas de solo exposto e de vegetação rala aumentaram $29,14 \%$ e $13,25 \%$, respectivamente.

As áreas de corpos d'água diminuíram consideravelmente, chegando a uma perda de $59,27 \%$ em 2010 . Isso é resultado da diminuição da vegetação localizada às margens dos rios e igarapés e da diminuição na quantidade e intensidade das chuvas que, segundo Silva et al. (2016), no período de 1970 a 2009, Santarém apresentou tendência à redução no regime pluviométrico de 1755,5 mm por ano.

Na Figura 7, mostra-se o gráfico comparativo para melhor visualização dessas mudanças.

Figura 7: Mudança na cobertura do solo entre os anos de 1986 a 2010

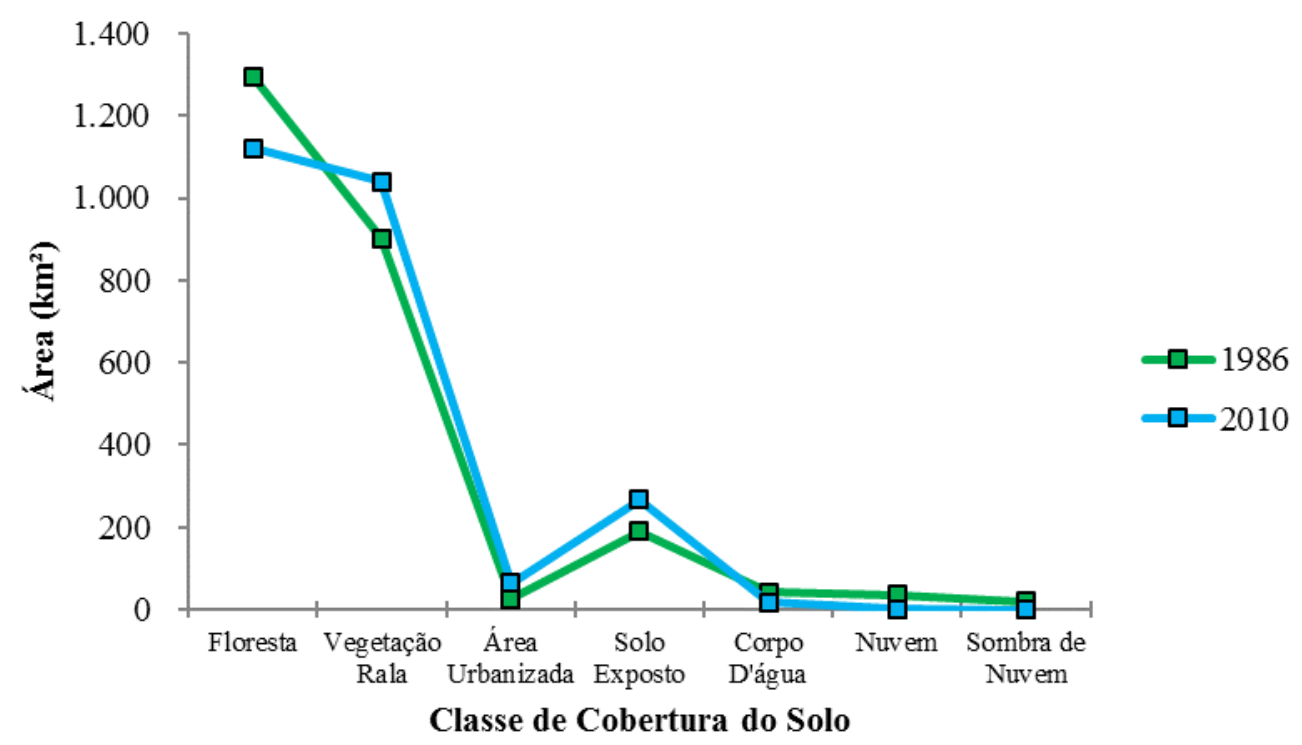

\section{Temperatura de superfície}

As temperaturas de superfície obtidas por meio do método METRIC/SEBAL foram divididas em 7 classes para facilitar a organização das informações e melhorar a interpretação dos resultados. Na Figura 9, é possível observar que as áreas com temperaturas abaixo de $29 \stackrel{\circ}{\circ}$ predominavam no ano de 1986 , enquanto que as temperaturas mais altas, acima de $32{ }^{\circ} \mathrm{C}$, eram bem menos frequentes. 
Figura 8: Temperatura de superfície no ano de 1986

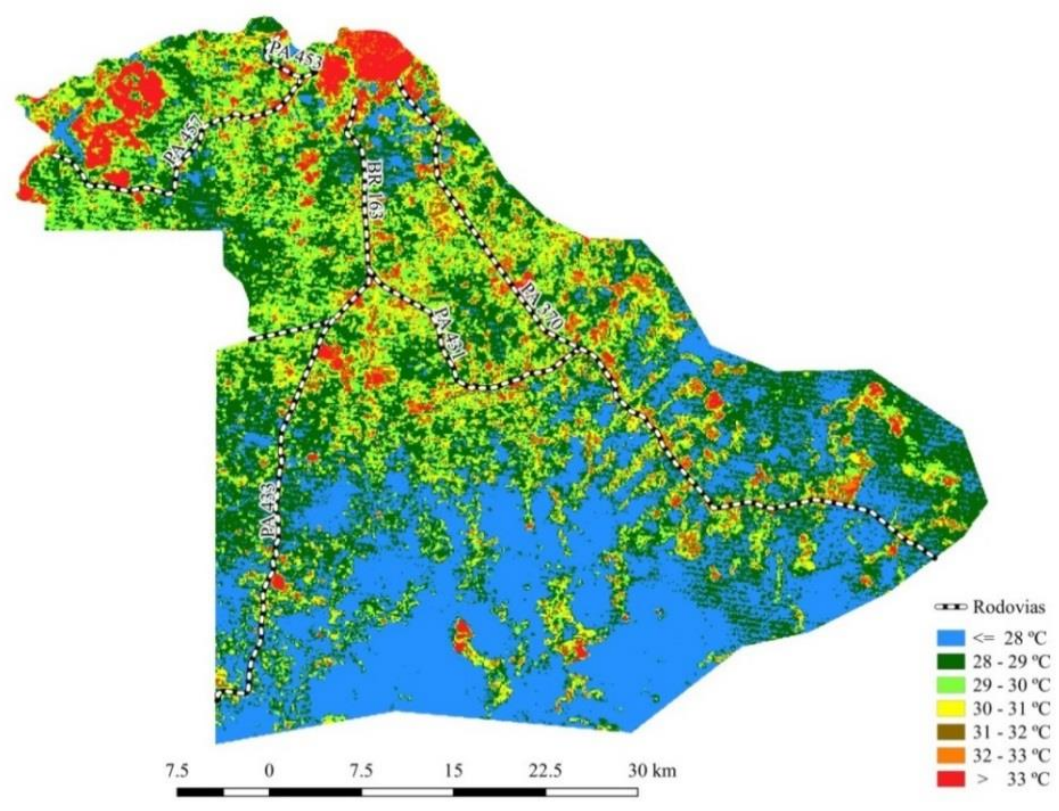

No ano de 2010, as áreas com temperaturas mais baixas diminuíram, enquanto que as áreas com temperaturas mais altas aumentaram consideravelmente sua extensão, como mostra a Figura 9.

Figura 9: Temperatura de superfície no ano de 2010

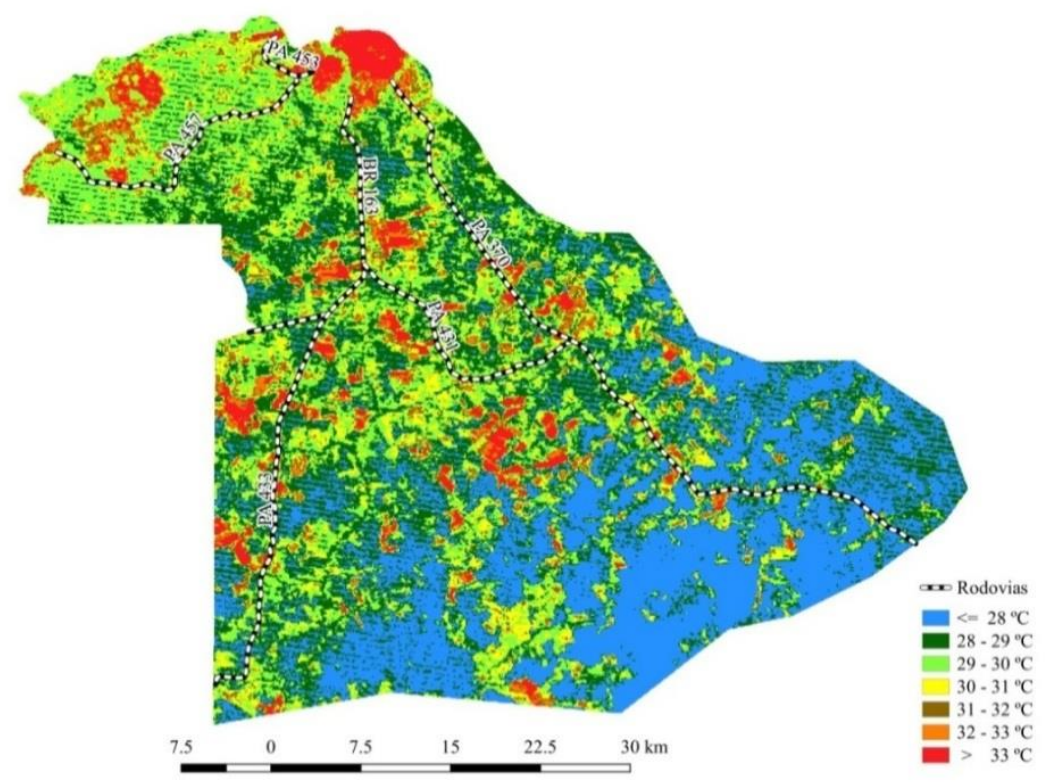

As mudanças ocorridas nas temperaturas, em valores quantitativos, podem ser facilmente visualizadas na Tabela 6 e na Figura 10. 
Tabela 6: Valores quantitativos das classes de temperatura

\begin{tabular}{|c|c|c|c|c|}
\hline Classe & $\begin{array}{c}\text { Área em } 1986 \\
\left(\mathrm{~km}^{2}\right)\end{array}$ & $\begin{array}{c}\text { Área em } 2010 \\
\left(\mathrm{~km}^{2}\right)\end{array}$ & $\begin{array}{c}\text { Mudança } \\
\left(\mathrm{km}^{2}\right)\end{array}$ & $\%$ \\
\hline$<=28 \stackrel{\circ}{\circ}$ & 775,57 & 697,16 & - 78,42 & 10,11 \\
\hline $28-29 \stackrel{\circ}{C}$ & 788,09 & 698,99 & $-89,1$ & $\begin{array}{r}- \\
11,30\end{array}$ \\
\hline $29-30^{\circ} \mathrm{C}$ & 402,01 & 554,37 & $+152,36$ & $\stackrel{+}{+}$ \\
\hline $30-31^{\circ} \mathrm{C}$ & 246,47 & 261,23 & $+14,76$ & $+5,65$ \\
\hline $31-32^{\circ} \mathrm{C}$ & 123,43 & 101,13 & $-22,3$ & 18,06 \\
\hline $32-33^{\circ} \mathrm{C}$ & 65,85 & 68,25 & $+2,39$ & $+3,51$ \\
\hline$>33^{\circ} \mathrm{C}$ & 91,93 & 102,35 & $+10,42$ & $\stackrel{+}{+} 10^{-}$ \\
\hline $\begin{array}{c}\text { Total da área de } \\
\text { estudo }\end{array}$ & & $2.516,94 \mathrm{~km}^{2}$ & & \\
\hline
\end{tabular}
a 2010

Figura 10: Mudança na temperatura de superfície entre os anos de 1986

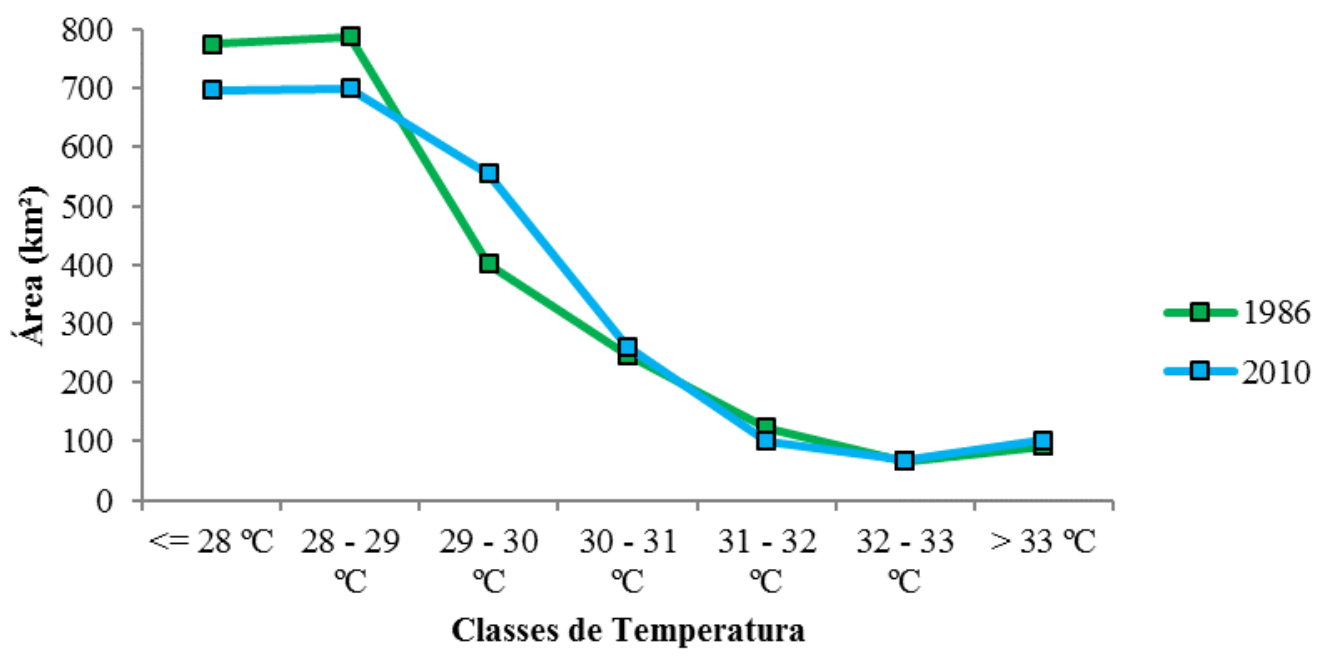

Observa-se na Tabela 6 que as áreas com temperaturas mais baixas diminuíram de tamanho e deram lugar a áreas com temperaturas mais altas. Até 2010 , as áreas com temperaturas na classe de $\leq$ a $28{ }^{\circ} \mathrm{C}$ diminuíram $78,42 \mathrm{~km}^{2}$, equivalente a $10,11 \%$ da área em 1986, assim como a classe de 28 - $29{ }^{\circ} \mathrm{C}$ teve uma redução de área em $11,30 \%$. 
As áreas com temperaturas mais altas, acima de $29{ }^{\circ} \mathrm{C}$, tenderam a aumentar. É possível ver que a classe de temperatura com maior crescimento em área foi a de 29 - $30{ }^{\circ} \mathrm{C}$, com crescimento de $27,48 \%$ em comparação ao ano de 1986. Em contrapartida, a classe com temperaturas entre 31 - $32{ }^{\circ} \mathrm{C}$ teve uma diminuição de $18,01 \%$. Isso pode ser resultado do aumento de temperatura nessas áreas, elevando-as a classes de temperatura acima de $32{ }^{\circ} \mathrm{C}$, pois estas tiveram um aumento considerável, em que a classe de 32 - $33^{\circ} \mathrm{C}$ teve um aumento de $3,51 \%$, e as áreas com temperaturas acima de $33^{\circ} \mathrm{C}$ cresceram $10,17 \%$.

\section{Cobertura do solo e temperatura}

A vegetação influencia na temperatura de superfície por causa de sua capacidade de absorver energia e servir como uma barreira que impede a incidência de energia diretamente no solo, conforme constatado por Jabert (2012), que utilizou micrologger's à sombra de árvores e outros expostos à luz solar direta para coleta da temperatura e umidade relativa do ar no município de Santarém-PA. Nesse trabalho, foi comprovado que a vegetação influenciou nas temperaturas médias locais, pois, nos instrumentos à sombra, as temperaturas obtidas foram significativamente menores que nos instrumentos colocados à luz solar direta.

Pode-se observar que no ano de 1986 as florestas predominavam na cobertura do solo, e as áreas com temperaturas altas eram consideravelmente menores. A Figura 12 mostra a cobertura do solo e a temperatura de superfície do ano de 1986. 
Figura 21: Cobertura do solo e temperatura de superfície no ano de

1986

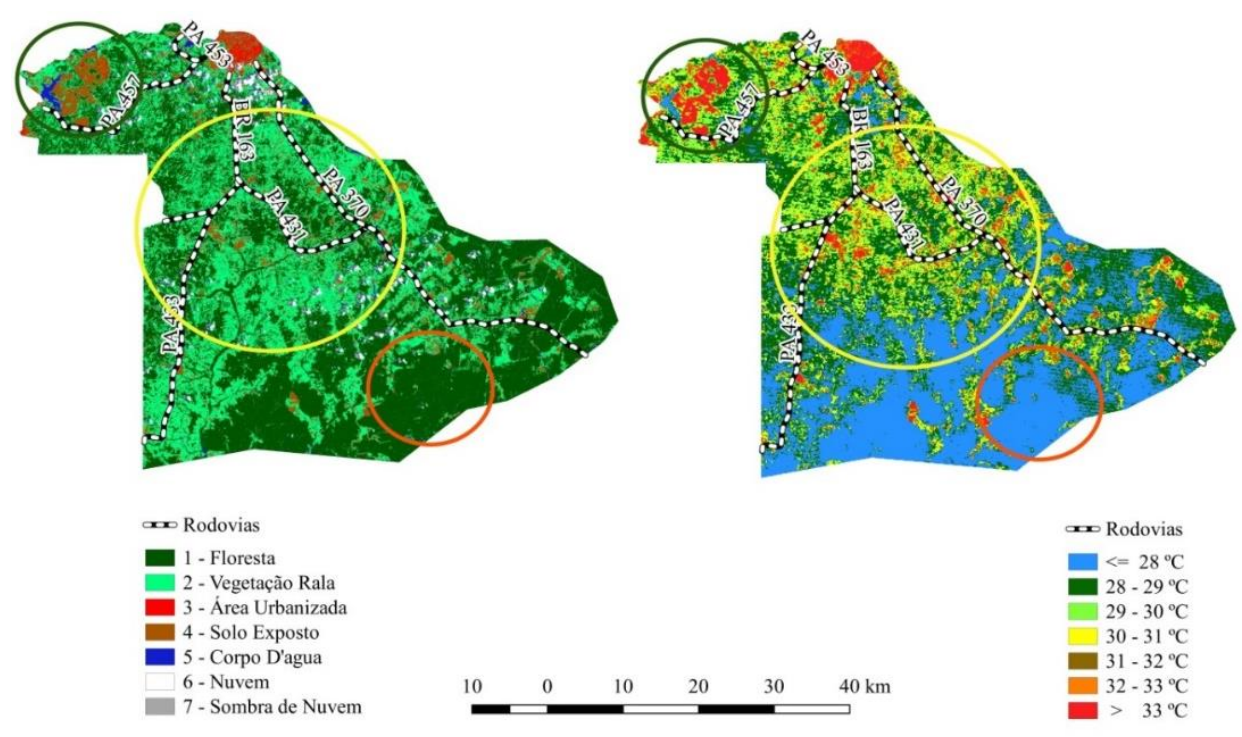

Na imagem acima, observa-se que, nas áreas onde a predominância era de florestas e corpos d'água, a temperatura de superfície era de $28{ }^{\circ} \mathrm{C}$ ou menor, conforme destacado pelas elipses vermelhas.

$\mathrm{Na}$ água, as temperaturas baixas ocorrem em virtude de sua baixa reflectividade, pois, dessa forma, a energia é absorvida, e ao alto calor específico que ela possui $\left(1 \mathrm{cal} / \mathrm{g}^{\circ} \mathrm{C}\right)$ faz com que a quantidade de energia necessária para aumentar sua temperatura seja muito grande (MASHIKI, 2012).

Nas áreas de florestas destacadas pela elipse laranja, a temperatura tende a ser baixa, pois o albedo das árvores é baixo, mas a transmissividade é alta. Portanto, grande parte da energia incidida nas folhas acaba sendo absorvida e transmitida para o metabolismo da planta, assim o calor não fica acumulado na superfície das folhas (ROMERO, 2011).

Mesmo ao longo das rodovias, as áreas com florestas e vegetação rala eram bastante expressivas e consequentemente as temperaturas eram mais amenas, variando entre 28 a $31^{\circ} \mathrm{C}$, conforme destacado pelas elipses amarelas.

A área de savana, circulada pela elipse verde, confundiu-se com o solo exposto em razão de suas características. Como suas respostas espectrais são muito parecidas, essa área apresentou temperaturas elevadas. É possível observar que as áreas de solo exposto eram bem menores e que as temperaturas nessas áreas eram acima de $32{ }^{\circ} \mathrm{C}$. 
A temperatura do solo exposto é muito alta por causa de seu baixo albedo e baixa transmissividade. Assim, a energia incidida nessa superfície fica acumulada e eleva a temperatura rapidamente (MASHIKI, 2012).

As áreas urbanizadas, que em 1986 cobriam uma área de 25,55 km², apresentaram uma temperatura elevada, acima de $32{ }^{\circ} \mathrm{C}$, assemelhando-se muito com a classe de solo exposto. Isso ocorre pelo fato de os materiais empregados na construção civil, como concreto, asfalto, telhas, apresentarem baixo grau de reflectividade. Dessa forma, grande parte da energia incidida nessas superfícies acaba ficando acumulada, gerando o aumento de temperatura (BIAS et al, 2003).

Na Figura 12, é possível observar as mudanças ocorridas na cobertura do solo e na temperatura de superfície após 24 anos.

Figura 3: Cobertura do solo e temperatura de superfície no ano de 2010

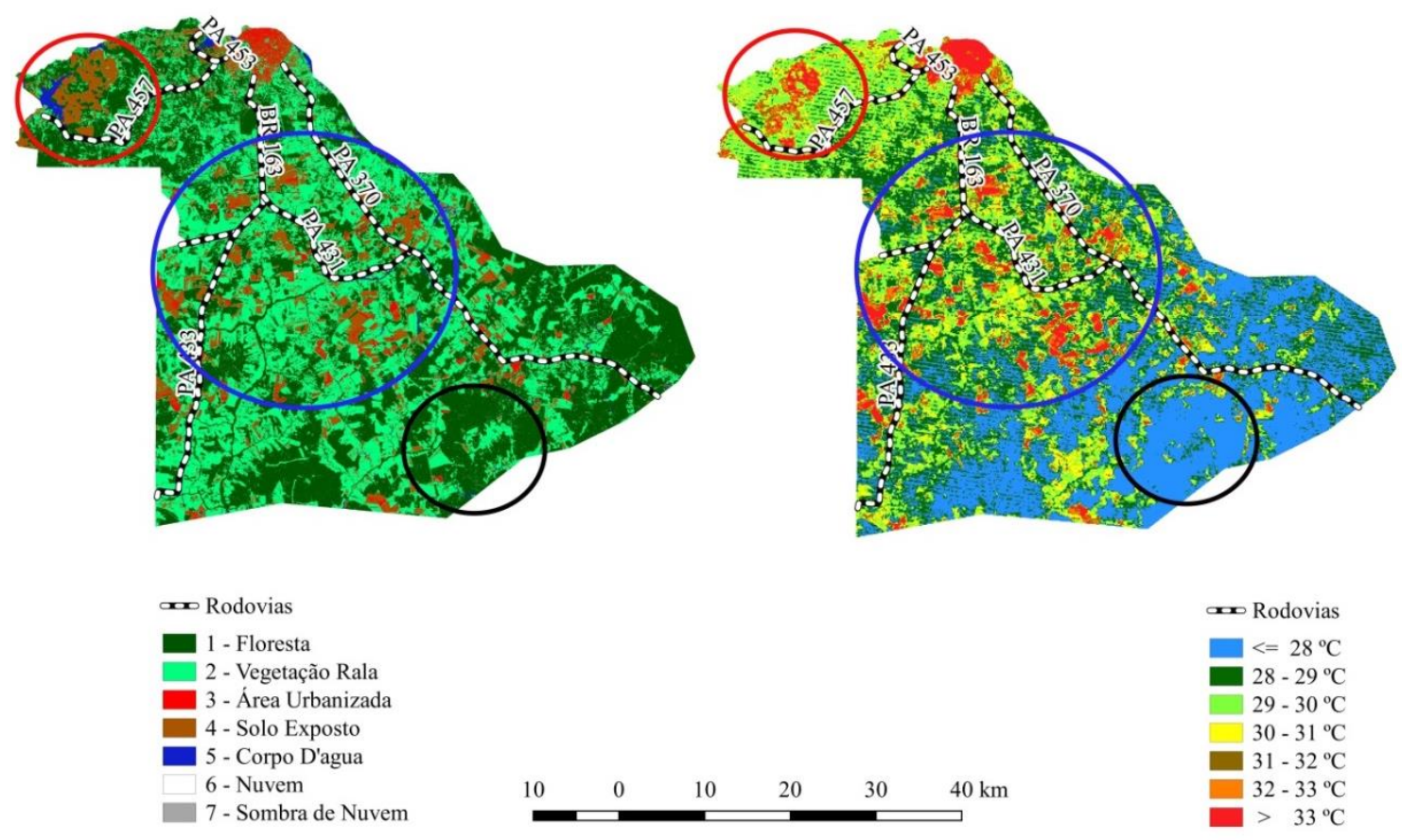

Essa imagem mostra que as áreas de solo exposto tiveram um aumento considerável. Isso ocorreu principalmente nas áreas periurbanas ao longo das rodovias BR 163, PA 370, PA 431 e PA 433. De acordo com Torres (2017), essa mudança teve como um dos incentivos principais o início das atividades em Santarém do terminal da empresa multinacional Cargill, no ano de 2003, pois os produtores, com 0 interesse de produzir seus produtos mais próximos a esse terminal, foram se instalando nas margens das referidas rodovias. Assim, as áreas 
que antes eram cobertas por florestas ou vegetação rala deram lugar a extensas áreas de solo exposto. Consequentemente, as temperaturas nessas áreas aumentaram, como pode ser visto na delimitação feita pela elipse azul.

As áreas urbanizadas, assim como as áreas de solo exposto, aumentaram bastante em relação ao ano de 1986. Conforme exposto por Venturieri et al (2007), isso é resultado, em parte, do êxodo rural, pois muitas pessoas venderam suas terras para grandes agricultores e mudaram-se para a zona urbana da cidade, ocorrendo assim um inchaço populacional e a substituição da cobertura vegetal pela construção civil, o que ocasionou o aumento da temperatura.

$\mathrm{Na}$ área de destaque da elipse vermelha, é possível ver que a extensão dos corpos d'água diminuiu, e a temperatura aumentou, ficando na faixa de 29 e $30^{\circ} \mathrm{C}$. Isso se justifica pela remoção de grande parte da mata ciliar, pelo crescimento de áreas urbanizadas nos seus entornos e a diminuição do regime pluviométrico.

$\mathrm{Na}$ área de destaque da elipse preta, a diferença de temperatura entre as áreas de florestas e a vegetação rala é facilmente visualizada. As áreas de florestas apresentaram temperatura $<=$ a $28 \stackrel{\circ}{\circ}$, enquanto que na vegetação rala a temperatura variou de 28 a $31^{\circ} \mathrm{C}$.

Em algumas áreas, a temperatura de superfície pode ter sido superestimada por eventual desgaste e descalibramento natural que o satélite Landsat 5 pode ter sofrido ao longo desses 24 anos em constante funcionamento.

\section{Considerações Finais}

Esse processo de venda de grandes áreas de terras a preços baixos fez com que muitas pessoas que residiam e desenvolviam suas atividades na zona rural procurassem outra alternativa de vida na zona urbana. Essas pessoas foram ocupando, principalmente, as periferias da cidade. De acordo com Venturieri et al (2007), o resultado disso é que as áreas onde antes eram ocupadas por pequenas áreas de pastagem ou agricultura para o autoconsumo deram lugar a grandes extensões de terras com agricultura mecanizada; e nas cidades a cobertura vegetal foi cada vez mais sendo suprimida para dar lugar à construção civil e à pavimentação de vias. 
A diminuição da cobertura vegetal ocasionada por essas mudanças ocorrentes com o passar do tempo gera ilhas de calor ${ }^{6}$. As ilhas de calor são intensificadas ou atenuadas de acordo com o albedo ou reflectividade da superfície terrestre, sendo esse a quantidade de radiação que uma superfície pode refletir. Quanto maior o albedo, menos energia fica retida na superfície.

Dessa forma, naturalmente, a temperatura dos centros urbanos é, em geral, mais elevada que a temperatura dos ambientes rurais em razão da predominância da cobertura asfáltica, verticalização dos prédios e ausência de cobertura vegetal, causando um grande desconforto térmico para as pessoas ${ }^{7}$.

Portanto, todas essas questões implicam no aumento da temperatura no município de Santarém, sobretudo nas áreas urbanas e periurbanas, ou seja, nas áreas onde ocorre a periferização da cidade e a expansão do agronegócio nas áreas de planalto do município. Desta forma, tem-se como resultado do estudo a classificação supervisionada por meio do método MAXIVER que mostrou-se muito eficaz na distinção da cobertura do solo com base nas amostras definidas. $O$ modelo METRIC/SEBAL, conforme comprovado por diversos autores, também mostrou excelentes resultados na obtenção de temperatura de superfície. Foi possível constatar que de 1986 a 2010 muitas mudanças ocorreram na superfície terrestre. O solo perdeu grande parte da cobertura vegetal, onde a temperatura era mais amena, e ganhou área urbanizada e área com solo exposto, que apresentaram temperaturas bastante elevadas. Essas mudanças ocorreram principalmente ao longo das rodovias que cortam o município e onde há maior quantidade de pessoas. Outro fator importante observado é que algumas áreas, apesar de serem visualmente diferentes, apresentam características físicas parecidas, como a confusão ocorrida entre as áreas de savana e solo exposto, e entre solo exposto e área urbanizada.

Apesar dos resultados serem bastante satisfatórios, é impossível ter exatidão em razão dos procedimentos estatísticos utilizados, das datas e do período do ano de passagem de sensor, da média resolução espacial das imagens, além do desgaste e descalibração que podem ocorrer com os satélites durante um longo período de utilização. Para alcançar essa precisão, sugere-se a utilização de

\footnotetext{
${ }^{6}$ Conforme exposto por Nascimento (2010), as ilhas de calor são áreas onde a temperatura é mais alta que no seu entorno. Isso ocorre principalmente nas áreas urbanas onde há intensa pavimentação, degradação e ausência de vegetação, podendo ocorrer também nas áreas rurais, caso estejam degradadas ou secas.

7 Conforto térmico é a sensação de bem-estar relacionada com a temperatura. É uma percepção em que uma pessoa saudável não sente nem calor demais nem muito frio (GOMES e AMORIM, 2003).
} 
metodologias que necessitam de dados coletados em campo, como o modelo SEBAL completo.

Por fim, destaca-se que o avanço do agronegócio na Amazônia vem causando grandes impactos, principalmente no aumento da temperatura na área urbana como é o caso do Município de Santarém, coincidindo com as áreas de solo exposto no resultado da análise apresentada do ano de 2010, e o vetor de expansão urbana a partir das rodovias, sendo que de 1986 a 2010 observa-se um decréscimo da cobertura vegetal de $13,5 \%$ do município. Consequentemente, a mudança da paisagem no município é considerável em relação a primeira imagem analisada, implicando nos fatores que elevam a temperatura na região e mudanças na paisagem e consequentemente no modo de vida camponês e urbano neste município contribuído para os conflitos agrários na região e para o aumento do desconforto térmico, sobretudo a população urbana de Santarém.

\section{REFERÊNCIAS}

ALLEN, R. G.; TASUMI, M.; MORSE, A.; TREZZA, R. A Landsat-based energy balance and evapotranspiration model in Western US water rights regulation and planning. Irrigation and Drainage Systems, v. 19, n. 3, p. 251-268, 2005. Disponível em:

<https://link.springer.com/content/pdf/10.1007\%2Fs10795-005-5187-z.pdf>. Acesso em: 5 mar. 2018.

ALVES, C. D.; FLORENZANO, T. G.; PEREIRA, M. N. Mapeamento de áreas urbanizadas com imagens Landsat e classificação baseada em objeto. Revista Brasileira de Cartografia v. 02, n. 62, 2010. Disponível em:

<https://www.researchgate.net/publication/257180711_Mapeamento_de_areas_urbanizadas _com_imagens_Landsat_e_classificacao_baseada_em_objeto> Acesso em: 19 mar. 2018.

AMAZÔNIA NOTÍCIA E INFORMAÇÃO. Banco de dados. Disponível em:

$<$ http://amazonia.org.br/2017/02/desmatamento-sa-de-sorriso-a-santarem-industria-da-sojatransforma-bacia-do-tapajos-em-um-tabuleiro-de-grandes-obras/>. Acesso em: 30 jan. 2018.

BARBOSA, A.P. Comparação de métodos de classificação de imagens, visando o gerenciamento de áreas citrícolas. Minas Gerais, 2009. 65p. Dissertação - (Mestrado em Agronomia). Universidade Estadual Paulista, Botucatu, 2009. Disponível em: <https://repositorio.unesp.br/handle/11449/90444>. Acesso: em 2 fev. 2018.

BASTIAANSSEN, W. G. M.; MENENTI, M.; FEDDES, R. A.; HOLTSLAG, A. A. M. A remote sensing surface energy balance algorithm for land (SEBAL). Journal of Hydrology. v. 212213, p. 198-212, 1998. Disponível em:

<https://www.sciencedirect.com/science/article/pii/S0022169498002534>. Acesso em: 5 mar. 2018.

BIAS, E.S.; BAPTISTA, G.M.M.; LOMBARDO, M.A. Análise do Fenômeno de ilhas de calor urbanas, por meio da combinação de dados Landsat e lkonos. In: XI SIMPOSIO 
BRASILEIRO DE SENSORIAMENTO REMOTO, 11., 2003, Minas Gerais. Anais eletrônicos... Minas Gerais: INPE, 2003. Disponível em:

<http://marte.sid.inpe.br/col/ltid.inpe.br/sbsr/2002/09.12.18.52/doc/14_005.pdf>. Acesso em: 30 jan. 2018.

BRAGA, A. C. Evapotranspiração e produtividade primária bruta em áreas agrícolas utilizando técnicas de sensoriamento remoto. Paraíba, 2014. 121p. Tese - (Doutorado em Meteorologia) - Universidade Federal de Campina Grande, Paraíba, 2014. Disponível em: <www.dca.ufcg.edu.br/posgrad_met/teses/AlexandraChavesBraga_2014.pdf >. Acesso em: 6 mar. 2018.

CÂMARA, G.; MEDEIROS, J. S. Geoprocessamento para projetos ambientais. São José dos Campos - SP: INPE, 1996. Disponível em:

<http://www.dpi.inpe.br/gilberto/tutoriais/gis_ambiente/>. Acesso em: 14 fev. 2018.

CHANDER, G.; MARKHAM, B. Revised Landsat-5 TM Radiometric Calibration Procedures and Postcalibration Dynamic Ranges. IEEE Transactions on Geoscience and Remote Sensing, v. 41, n.11, Novembro, 2003. Disponível em:

<https://landsat.usgs.gov/sites/default/files/documents/L5_TM_Cal_2003.pdf>Acesso em: 5 mar. 2018.

COELHO, A. L. N.; CORREA, W. S. C. Temperatura de superfície Celsius do sensor TIRS/Landsat-8: Metodologia e Aplicações. Revista Geográfica Acadêmica, v. 7, n. 1, p. 31-45, 2013. Disponível em: < https://revista.ufrr.br/rga/article/view/2996>. Acesso em: 12 fev. 2018.

COHENCA D.; CARVALHO, R. Comparação de métodos de classificação OBIA, Máxima Verossimilhança e Distância Mínima em imagem OLI/Landsat-8 em área de alta diversidade de uso do solo. In: XVII SIMPÓSIO BRASILEIRO DE SENSORIAMENTO REMOTO, 17., 2015, Paraíba. Anais eletrônicos... Paraíba: INPE. Disponível em:

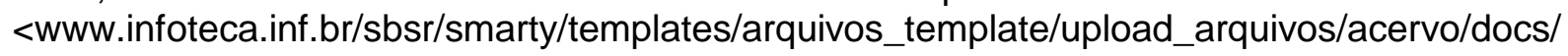
p0193.pdf>. Acesso em: 1 mar. 2018.

CUNHA, J. E. B. L.; RUFINO, I. A. A.; IDEIÃO, S. M. A. Determinação da temperatura de superfície na cidade de Campina Grande-PB a partir de imagens do satélite Landsat 5TM. In: XIV SIMPÓSIO BRASILEIRO DE SENSORIAMENTO REMOTO, 14., 2009, Rio Grande do Norte. Anais eletrônicos... Rio Grande do Norte: INPE, 2009. Disponível em: <http://marte.sid.inpe.br/col/dpi.inpe.br/sbsr@80/2008/11.17.22.51/doc/5717-5724.pdf>. Acesso em: 5 mar. 2018.

DEMARCHI, C. J; SARTORI, A. A. C; ZIMBACK, C. R. L. Métodos de classificação de imagens orbitais para o mapeamento do uso do solo: estudo de caso na Sub-Bacia do Córrego das Três Barras. In: XV Simpósio Brasileiro de Sensoriamento Remoto, 15., 2011, Curitiba. Anais eletrônicos... Curitiba: INPE. Disponível em:

<http://marte.sid.inpe.br/col/dpi.inpe.br/marte/2011/07.12.13.25/doc/p0678.pdf> Acesso em: 1 mar. 2018.

EMPRESA BRASILEIRA DE PESQUISA AGROPECUÁRIA (EMBRAPA). Bando de Dados da Embrapa. Disponível em: < https://www.cnpm.embrapa.br/projetos/sat/conteudo/missao_landsat.html>. Acesso em 1 jan. 2018

GOMES, M. A. S.; AMORIM, M. C. C. T. Arborização e conforto térmico no espaço urbano: estudo de caso nas praças públicas de Presidente Prudente (SP). Caminhos de Geografia. v. 7, n. 10, p. 94-106, 2003. Disponível em:

<http://www.seer.ufu.br/index.php/caminhosdegeografia/article/viewFile/15319/8618>.

Acesso em: 1 fev. 2018. 
GONÇALVES, D. C. M.; GAMA, J.R.V.; F. A, OLIVEIRA.; JUNIOR, R.C.O.; ARAUJO, G.C.; ALMEID, L.S. Aspectos Mercadológicos dos Produtos não Madeireiros na Economia de Santarém-Pará, Brasil. Rev. Floresta e Ambiente. Seropédica, v.19, n.1, p. 9-16 2012; Disponível em: < http://www.floram.org/files/v19n1/v19n1a2.pdf>. Acesso em: 6 set. 2016.

GRONDONA, A. E. B. Avaliação da acurácia dos classificadores de máxima verossimilhança, mínima distância euclidiana e isodata na classificação de imagens da região do Pantanal. In: II SIMPÓSIO DE GEOTECNOLOGIAS NO PANTANAL CORUMBÁ, MS, 2., 2009, Mato Grosso do Sul. Anais eletrônicos... Mato Grosso do Sul: EMBRAPA, 2009. Disponível em: <https://www.geopantanal.cnptia.embrapa.br/2009/cd/p100.pdf>. Acesso em: 27 fev. 2018.

IDEIÃO, S. M. A.; CUNHA, J. E. B. L.; RUFINO, I. A. A.; SILVA, B. B. Determinação da temperatura de superfície no Estado da Paraíba a partir de imagens Landsat 5-TM. In: II SIMPÓSIO DE CIÉNCIAS GEODÉSICAS E TECNOLOGIAS DA GEOINFORMAÇÃO. 2., Recife: Anais eletrônicos... Recife: UFCG. Disponível em:

<http://www.hidro.ufcg.edu.br/twiki/pub/GeoTermal0/Publica\%EF\%BF\%BD\%EF\%BF\%BDes geotermal/simgeo-artigo.pdf>. Acesso em: 5 mar. 2018.

INSTITUTO BRASILEIRO DE GEOGRAFIA E ESTATÍSTICA (IBGE). Banco de Dados. Disponível em: <http://cidades.ibge.gov.br/xtras/perfil.php?codmun=150680>. Acesso em: 1 fev. 2018;

JABERT, D. J. A influência da vegetação no índice de conforto térmico em praças de diferentes configurações morfológicas na cidade de Santarém-PA. Santarém, 2012. 71p. Dissertação (Mestrado em Recursos Naturais) - Universidade Federal do Oeste do Pará, Santarém, 2012. Disponível em: <http://www.ufopa.edu.br/academico/posgraduacao/banco-de-teses/ppgrna/2010/diniz-junior-jabert/at_download/file>. Acesso em: 4 ago. 2016.

LIMA, V.; AMORIM, M. C. C. T. A importância das áreas verdes para a qualidade ambiental das cidades. Revista Formação. São Paulo, 2006, v. 1, n.13, p. 139 - 165. Disponível em: <http://revista.fct.unesp.br/index.php/formacao/article/viewFile/835/849>. Acesso em: 22 jul. 2016.

MACHADO, C. C. C.; GALVÍNCIO, J. D.; SILVA, B. B.; OLIVEIRA, T. H.; PEREIRA, E. C. G. Impacto da correção atmosférica no cômputo do albedo e do IVAS no PARNA Catimbau (PE-Brasil) utilizando imagens TM - Landsat 5 e o Sebal/Metric. In: XV SIMPÓSIO BRASILEIRO DE SENSORIAMENTO REMOTO, 15., 2011, Paraná. Anais eletrônicos... Paraná: INPE, 2011. Disponível em:

<http://marte.sid.inpe.br/col/dpi.inpe.br/marte/2011/07.20.18.32/doc/p0675.pdf >. Acesso em: 5 mar. 2018.

MASHIKI, M. Y. Geoprocessamento na identificação de ilhas de calor e influência do uso e ocupação do solo na temperatura aparente da superfície no município de Botucatu/SP. Botucatu, 2012. 67p. Dissertação - (Mestrado em Agronomia). Universidade Estadual Paulista, Botucatu, 2012. Disponível em:

<https://repositorio.unesp.br/handle/11449/90507>. Acesso em: 1 jan. 2018.

MOREIRA, M. A. Fundamentos do sensoriamento remoto e metodologias de aplicação. 3 ed. Viçosa: Ed. UFV, 2007. 320p.

NASCIMENTO, D. T. F. Emprego de técnicas de sensoriamento remoto e de geoprocessamento na análise multitemporal do fenômeno de ilhas de calor no município de Goiânia-GO (1986/2010). Goiás, 2010, 98p. Dissertação - (Mestrado em 
Geografia). Universidade Federal de Goiás, Goiás, 2010. Disponível em: < https://repositorio.bc.ufg.br/tede/handle/tde/1860> Acesso em: 31 jan. 2018.

NERY, C. V. M. FERNANDES, F.H.S.; MOREIRA, A.A.; BRAGA, F.L. Avaliação das Técnicas de Classificação MAXVER, MAXVER-ICM e Distância Mínima Euclidiana de acordo com Índice Kappa. Revista Brasileira de Geografia Física, Pernambuco, 2013, v.6., n.2, p.320328. Disponível em: <https://periodicos.ufpe.br/revistas/rbgfe/article/view/232998> Acesso em: 1 mar. 2018.

SILVA, M. A. G.; JUNIOR, J. M. G.; SILVA, N. F. C.; SANTOS, F. C. V.; UCKER, F. E. Caracterização pluviométrica de Santarém-PA. Revista Eletrônica de Educação da Faculdade Araguaia, 10: 112-120, 2016. Disponível em: < https://www.fara.edu.br/sipe/index.php/renefara/article/download/435/pdf_61>. Acesso em: 28 mar. 2018.

PEREIRA, B. R.; MEES, M. B.; LEITE M. R.; FILHO, R. M. Análise da gestão ocupacional em Montes Claros - MG: Impactos do uso do solo e suas consequências na temperatura de superfície. Revista Cerrados, Montes Claros, v. 15, n. 1, p. 285-311, 2017. Disponível em: < https://dialnet.unirioja.es/servlet/articulo?codigo=6057059>. Acesso em: 5 mar. 2018.

PRIMAVESI, O.; ARZABE, C.; PEDREIRA, M.S.; Mudanças climáticas: visão tropical integrada das causas, dos impactos e de possíveis soluções para ambientes rurais ou urbanos. São Carlos: Embrapa Pecuária Sudeste, 2007. - (Embrapa Pecuária Sudeste. Documentos, 70). Disponível em: <https://www.embrapa.br/busca-de-publicacoes//publicacao/48017/mudancas-climaticas-visao-tropical-integrada-das-causas-dos-impactose-de-possiveis-solucoes-para-ambientes-rurais-ou-urbanos >. Acesso em: 31 jan. 2018.

PIRES, E. G.; FERREIRA Jr, L.G. Mapeamento da temperatura de superfície a partir de imagens termais dos satélites Landsat 7 e Landsat 8. In: XVII SIMPÓSIO BRASILEIRO DE SENSORIAMENTO REMOTO - INPE, 17., 2015, Paraíba. Anais eletrônicos... Paraíba: INPE, 2015. Disponível em: < www.dsr.inpe.br/sbsr2015/files/p1671.pdf> Acesso em: 18 fev. 2018.

RODRIGUES, T.W.P.; GUIMARAES, U.S.; ROTTA, L.H.S.; WATANABE, F.S.Y.; ALCANTARA, E.; IMAI, N.N. Delineamento amostral em reservatórios utilizando imagens Landsat-8/OLI: um estudo de caso no reservatório de Nova Avanhandava (Estado de São Paulo, Brasil). Boletim de Ciências Geodésicas, Curitiba, v. 22, n. 2, p. 303-323, 2016. Disponível em: < http://www.redalyc.org/html/3939/393946272007/>. Acesso em: 13 fev. 2018.

ROMERO, M. A. B. Correlação entre o microclima urbano e a configuração do espaço residencial de Brasília. Fórum Patrimônio. v. 4, n. 1, 2011. Disponível em <http://forumpatrimonio.com.br/seer/index.php/forum_patrimonio/article/view/11> Acesso em: 22 mar. 2018.

SANTARÉM. Prefeitura Municipal de Santarém. Banco de Dados. Disponível em: < http://www.santarem.pa.gov.br/pagina.asp?id_pagina=6>. Acesso em: $1 \mathrm{fev} .2018$. SILVA, B.E.B. Análise dos impactos das diferentes formas de ocupação da superfície sobre as condições meteorológicas na região de Santarém, Pará. Pará, 2011, 94p. Dissertação - (Mestrado em Ciências Ambientais). Universidade Federal do Pará, Museu Paraense Emilio Goeldi e EMBRAPA, Pará, 2011. Disponível em: <http://repositorio.ufpa.br/jspui/handle/2011/6833>. Acesso em: 30 jan. 2018.

SILVA, V. P. R.; SÁ, J. A.; TELES, V. O.; OLIVEIRA, C. W. Obtenção da temperatura da superfície do Cariri com uso do Metric. Cadernos de Cultura e Ciência, Crato, v. 11, n. 2, p.508, 2012. Disponível em: 
<http://periodicos.urca.br/ojs/index.php/cadernos/article/view/508/pdf_1> Acesso em: 5 mar. 2018.

VENTURIERI, A.; COELHO, A.S.; THALES, M.C.; BACELAR, M.D.R. Análise da expansão da agricultura de grãos na região de Santarém e Belterra, Oeste do estado do Pará. In: XIII SIMPÓSIO BRASILEIRO DE SENSORIAMENTO REMOTO., 2007, Florianópolis. Anais eletrônicos... Florianópolis: INPE, Disponível em: <https://www.embrapa.br/busca-depublicacoes/-/publicacao/974089/analise-da-expansao-da-agricultura-de-graos-na-regiao-desantarem-e-belterra-oeste-do-estado-do-para>. Acesso em: 31 jan. 2018.

\section{NOTAS DE AUTOR}

\section{CONTRIBUIÇÃO DE AUTORIA}

Everson Raylan Silva dos Santos - Concepção e elaboração do manuscrito. Coleta de dados Participação ativa da discussão dos resultados; Revisão e aprovação da versão final do trabalho.

Barbara Eleonora Santos Teixeira - Concepção e elaboração do manuscrito. Coleta de dados Participação ativa da discussão dos resultados; Revisão e aprovação da versão final do trabalho.

Everton Cristo de Almeida - Concepção e elaboração do manuscrito. Coleta de dados Participação ativa da discussão dos resultados; Revisão e aprovação da versão final do trabalho.

Ítalla Cristina Neves - Concepção e elaboração do manuscrito. Coleta de dados Participação ativa da discussão dos resultados; Revisão e aprovação da versão final do trabalho.

Ademir Terra - Elaboração do manuscrito, revisão e aprovação da versão final do trabalho.

\section{FINANCIAMENTO}

Não se aplica.

\section{CONSENTIMENTO DE USO DE IMAGEM}

Não se aplica.

\section{APROVAÇÃO DE COMITÊ DE ÉTICA EM PESQUISA}

Não se aplica.

\section{CONFLITO DE INTERESSES}

Não se aplica.

\section{LICENÇA DE USO}

Este artigo está licenciado sob a Licença Creative Commons CC-BY. Com essa licença você pode compartilhar, adaptar, criar para qualquer fim, desde que atribua a autoria da obra.

\section{HISTÓRICO}

Recebido em: 01-02-2019

Aprovado em: 28-03-2019 